\title{
Elucidating respective functions of two domains BIR and C-helix of human IAP survivin for precise targeted regulating mitotic cycle, apoptosis and autophagy of cancer cells
}

\author{
Fabiao Hu${ }^{1, *}$, Daxia Pan ${ }^{1, *}$, Wenyun Zheng ${ }^{2, *}$, Ting Yan', Xiujuan He ${ }^{2}$, Fuzheng Ren², \\ Yiming Lu ${ }^{3}$ and Xingyuan $\mathrm{Ma}^{1}$ \\ ${ }^{1}$ State Key Laboratory of Bioreactor Engineering, and School of Biotechnology, East China University of Science and \\ Technology, Shanghai 200237, China \\ ${ }^{2}$ Shanghai Key Laboratory of New Drug Design, and School of Pharmacy, East China University of Science and Technology, \\ Shanghai 200237, China \\ ${ }^{3}$ Department of Biochemical Pharmacy, School of Pharmacy, Second Military Medical University, Shanghai 200433, China \\ *These authors have contributed equally to this work \\ Correspondence to: Xingyuan Ma, email: maxy@ecust.edu.cn \\ Yiming Lu, email: bluesluyi@sina.com \\ Wenyun Zheng, email: zwy@ecust.edu.cn
}

Keywords: BIR and CC domains; survivin; cell cycle; apoptosis and autophagy; breast cancer cells

Received: September 08, $2017 \quad$ Accepted: November 13, $2017 \quad$ Published: December 01, 2017

Copyright: Hu et al. This is an open-access article distributed under the terms of the Creative Commons Attribution License 3.0 (CC BY 3.0), which permits unrestricted use, distribution, and reproduction in any medium, provided the original author and source are credited.

\section{ABSTRACT}

Survivin was the smallest member of the IAP family, which was over expressed in many different cancers, and considered to be a promising hot target for cancer therapy, and our previous study demonstrated that multiple dominant negative mutants from full-length survivin could have many complex effects on cancer cells, such as cell cycle, apoptosis, and autophagy. But it was not yet known what role the two main domains played in those functions, which would be very important for the design of targeted anticancer drugs and for the interpretation of their molecular mechanisms. In this study, based on preparation the two parts (BIR domain and CC domain) of survivin by genetic engineering and cell characterization assay, we discovered that BIR (T34A)-domain peptide could inhibit Bcap-37 cells growth in a dose- and time-dependent manner, increase the proportion of G2/M phase, and induce caspase-dependent apoptosis via the mitochondrial pathway. While CC (T117A)-domain peptide increased the proportion of S-phase cells and increased the level of the autophagy marker protein LC3B significantly. These further experiments confirmed that TAT-BIR (T34A) peptide could be used to inhibit cell proliferation, promote apoptosis, and block mitosis, and TAT-CC (T117A) peptide showed mainly to promote autophagy, process of DNA replication, and mitosis to breast cancer cells. This research will lay the foundation for interpreting the multifunction mechanism of survivin in cell fates, further make senses in developing the anticancer drugs targeting it precisely and efficiently.

\section{INTRODUCTION}

Survivin is the smallest member of the inhibitor of apoptosis (IAP) family, which is overexpressed in most of human tumors but not in normal tissues $[1,2]$. Overexpression of survivin not only plays a key role in the regulation of apoptosis and cell division [3], but also correlates with tumor progression and induces anticancer drug resistance $[4,5]$. Thus, it has become a potential oncotherapeutic target. Unlike other family members of IAP, survivin contains 142 amino acids and folds into two significant domains: a baculoviral IAP repeat (BIR) domain in the N-terminus (100aa) and an elongated $\alpha$-helical coiled-coil (CC) in the C-terminal (42aa) $[6,7]$ 
(Figure 1). X-ray crystallography data has shown two molecules of survivin can form a bowtie-shape dimer through a hydrophobic interface [8], which are formed by the 6-10 residues immediately prior to the BIR domain region at $\mathrm{N}$-terminal and the 14 residues (survivin 89-102) in the connecting region between the BIR domain and the C-terminal $\alpha$-helix structure [9]. Moreover, the differential functions of survivin seem to be caused by differential subcellular localization of this molecule [10]. Nuclear localization of survivin is mainly involved in spindle monitoring at mitosis, whereas cytoplasmic/mitochondrial survivin counteracts pro-apoptotic signals by preventing caspase- 9 and caspase-3 activation [11].

During mitosis, survivin is localized to various components of the mitotic apparatus, including centrosomes, microtubules of the metaphase and anaphase spindle, and the remnants of the mitotic apparatusmidbodies [12]. A direct association between survivin and polymerized tubulin has been demonstrated in vitro [13], potentially indicating the involvement of the $\mathrm{C}$-terminal $\alpha$-helices. Meanwhile, survivin can also promote mitosis by forming the chromosomal passenger complex (CPC) with Aurora-B kinase, inner centromere protein (INCENP), and Borealin [14]. The CPC facilitates the correction of maloriented chromosomes during prometaphase congression and the execution of cytokinesis $[15,16]$. Phosphorylation at threonine 117 of survivin by Aurora-B kinase was reported to regulate the entire chromosomal passenger complex in mammals [17]. Wheatley et al. [18] reported that, the non-phosphorylatable survivin (survivinT117A) could substitute for the wild type protein, while the phosphomimic (survivinT117E) could not restore viability, nor could it complement chromosome congression and spindle checkpoint defects that arose due to depletion of endogenous survivin.

Overexpression of survivin has been associated with inhibition of cell death initiated via the extrinsic or intrinsic apoptotic pathways [3]. Survivin interferes with the process of apoptosis through inhibition of different caspase activity by the interaction between the single BIR domain of survivin and different caspases [19]. In vitro study indicates that Thr34 phosphorylation of survivin by $\mathrm{CDC} 2$ is essential for the interaction of survivin with caspase-3, 7 and 9 [20]. Further studies have found that a mutation of Survivin(T34A) can induce the release of cytochrome $\mathrm{c}$ from the mitochondria, leading to apoptosis [21]. According to these studies, we discovered that single BIR domain of survivin interfered with the process of apoptosis through inhibition of different caspase activity. Therefore, we urgent to know that whether $\mathrm{CC}$ domain of survivin interferes with the process of apoptosis. In addition, autophagy is closely linked with apoptosis by shared regulatory systems and common pathways, indicating its relevance with apoptosis and important role in tumorigenesis [22]. Beclin-1 can positively regulate autophagy by combining with $\mathrm{PI} 3 \mathrm{KCIII} / \mathrm{Vps} 34$ and other positive co-factors such as Survivin, Akt, and Bcl2/Bcl- $X_{L}$ to form the Beclin-1 interactome [23]. Recent study indicates that interaction of Beclin-1 with survivin regulates sensitivity of human glioma cells to TRAIL (a death receptor ligand)-induced apoptosis [24]. Ectopic expression of survivin also significantly attenuated YM155-induced apoptosis and autophagy, whereas survivin siRNA induced autophagy [25]. Chang et al. [26] demonstrated that silencing survivin slightly influenced cell growth in HCC cells and induced the formation of autophagosomes. These literatures only explained that upregulation of survivin inhibited autophagy, while downregulation of survivin promoted autophagy. However, the mechanism of survivin regulating autophagy has not been resolved. For that reason, we speculated that whether BIR domain of survivin of cancer cells inhibited autophagy by inhibiting apoptosis, or CC domain of survivin also interfered autophagy.

Our previous studies demonstrated that multiple dominant negative mutants from full-length survivin could cause cancer cells to have many complex effects such as cell cycle, apoptosis, and autophagy [27, 28]. However, the role(s) and mechanisms that each domain may play in regulating the cell cycle, autophagy, and apoptosis, have not been reported. In this study, we separately prepared the two individual domains (BIR domain and $\mathrm{CC}$ domain) as the truncated versions of survivin (namely TATBIR(T34A) and TAT-CC(T117A) ) and systematically explored the functions of them in the cell cycle, apoptosis, and autophagy of breast cancer. We found that TAT-BIR (T34A) could be used to inhibit cell proliferation, promote apoptosis, and block mitosis, and TAT-CC (T117A) peptide showed mainly to promote autophagy, process of DNA replication, and mitosis to breast cancer cells.

\section{RESULTS}

\section{TAT-BIR(T34A) can inhibit growth of cultured breast cancer cell lines}

To establish whether these truncated versions of survivin could inhibit cell growth, the cell-inhibitory effect of TAT-BIR(T34A), TAT-CC(T117A), and TATSurvivin(T34/117A) were determined by MTT assay on human breast carcinoma cell lines Bcap-37. After treated with a various concentrations of TAT-CC(T117A), TATBIR(T34A), and TAT-Survivin(T34/117A) (7.5, 15, 30, 60, and $90 \mu \mathrm{g} / \mathrm{mL}$, respectively), the viability of Bcap-37 cells decreased in a dose-dependent manner (Figure 2A). The cell viability of Bcap-37 cells treated with TAT-CC(T117A) decreased from $100 \%$ to $90.2 \%$, TAT-BIR(T34A) from $100 \%$ to $64.6 \%$, and TAT-Survivin(T34/117A) from $100 \%$ to $56.1 \%$. These data demonstrated that TATBIR(T34A), the single domain of survivin, still could inhibit cell growth, and showed anticancer effect similar to that of the full-length TAT-Survivin(T34/117A), while 
TAT-CC(T117A) had little effect on cell proliferation. Specifically, the cell viability of Bcap-37 cells incubated with $60 \mu \mathrm{g} / \mathrm{mL}$ TAT-BIR(T34A) exhibited a gradually decline for 12, 24, 48 and $72 \mathrm{~h}$, respectively (Figure 2B). Meanwhile, we witnessed the remarkable morphological changes that embody early apoptosis of treated cells, such as irregular shape, shrinkage, and the rough edge (Figure 2C). Therefore, the anti-proliferation activity of TAT-BIR(T34A) showed the dose- and time-dependent.

Annexin V-FITC/PI experiment was carried out to further determined the effect of TAT-BIR(T34A) and TAT-Survivin(T34/117A) on cell apoptosis. After treated with different concentrations $(30,60$, and $90 \mu \mathrm{g} / \mathrm{mL})$ of TAT-BIR(T34A), the apoptosis rate of Bcap-37 cells increased gradually (Figure 3A). Apoptosis rate was 3.2\% and $35.2 \%$ when incubated with $30 \mu \mathrm{g} / \mathrm{mL}$ and $90 \mu \mathrm{g} / \mathrm{mL}$ TAT-BIR(T34A) for $36 \mathrm{~h}$, respectively. When the treated time was $60 \mathrm{~h}$, it changed to $4.4 \%$ and $56.8 \%$, showing an approximately dose- and time-dependent. These above results suggested that BIR(T34A) domain could promote apoptosis of Bcap-37 cells. Moreover, it was also found that cell apoptosis in TAT-Survivin(T34/117A) group was higher than that in TAT-BIR (T34A) group (Figure 3B).

To confirm the main apoptotic pathway of Bcap-37 cells induced by TAT-BIR(T34A), TAT-CC(T117A), and TAT-Survivin(T34/117A), the expression of apoptosisassociated proteins, activated caspase-9, activated caspase- 3 and survivin, were analyzed by Western blot. Compared with the control group, the level of survivin descended significantly and activated caspase- 3 increased in the Bcap-37 cells treated with each of the three proteins for $48 \mathrm{~h}$. However, the level of activated caspase- 9 increased slightly. It was noteworthy that the treatment of TAT-Survivin(T34/117A) resulted in a more significant increase of activated caspase-3 (Figure 4). The above mentioned results indicated that, pro-apoptosis associated proteins activated caspase- 9 and caspase- 3 increased, whereas anti-apoptosis associated proteins survivin decreased in Bcap-37 cells treated with each of the three proteins.

\section{Effects of TAT-BIR(T34A), TAT-CC(T117A), and TAT-Survivin(T34/117A) on cell cycle of Bcap-37 cells}

To determine the function of these proteins in the regulation of cell cycle, the distribution of cell cycle in Bcap-37 cells treated with TAT-BIR(T34A), TATCC(T117A), and TAT-Survivin(T34/117A) was analyzed by flow cytometry. In comparison with the control group, cell proportion of $\mathrm{G} 0 / \mathrm{G} 1$ phase all declined in the treated group, and cell proportion of $\mathrm{G} 2 / \mathrm{M}$ phase and $\mathrm{S}$ phase showed the different change in Bcap-37 cells. The cell proportion of G0/G1 phase in TAT-BIR(T34A)- and TATSurvivin(T34/117A)-treated group exhibited a slight decrease, which were $6.47 \%$ and $4.27 \%$, respectively.
However, the cell proportion of $\mathrm{G} 2 / \mathrm{M}$ phase in TATBIR(T34A)- and TAT-Survivin(T34/117A)-treated group both increased by $5 \%$. It was surprised that TAT$\mathrm{CC}(\mathrm{T} 117 \mathrm{~A})$ treatment led to the proportion of cells in G0/G1 phase decreased significantly by $14.6 \%$, and the proportion of cells in $\mathrm{S}$ phase increased by $22.17 \%$, from $19.33 \%$ to $42.10 \%$ (Figure $5 \mathrm{~A}$ ). All the evidences suggested that TAT-BIR(T34A) and TAT-Survivin(T34/117A) treatment arrested cell cycle at G2/M phase in Bcap-37 cells, and showed the similar effects on the distribution of the cell cycle. However, TAT-CC(T117A) displayed the different functions, which enabled proportion of cells in $\mathrm{G} 0 / \mathrm{G} 1$ phase fell sharply, and proportion of cells in $\mathrm{S}$ phase increased significantly (Figure 5B). It demonstrated that the $\mathrm{CC}$ domain promoted the Bcap-37 cells to leave the $\mathrm{G} 0 / \mathrm{G} 1$ resting phase and to enter the stage of DNA replication, and thus promoting cell division.

Cyclin D1 is a protein that regulates cell cycle, which is first synthesized in the cell cycle and peaked at mid-G1 phase [29]. Hence, the expression of Cyclin D1 was determined by Western blot. The results illustrated that the expression of Cyclin D1 decreased in Bcap-37 cells treated with three recombinant proteins (Figure 6), namely that the proportion of cells in G1 phase decreased resulted from Cyclin D1 decreased. However, the Cyclin D1 level of TAT-CC(T117A)-treated group was higher than that in TAT-BIR(T34A) group and TAT-Survivin(T34/117A) group, suggesting TAT-CC(T117A) could promote Bcap37 cells to leave the $\mathrm{G} 0 / \mathrm{G} 1$ resting phase, and enter the stage of DNA replication. These results were consistent with the observations in flow cytometry analysis lowered proportion of cells in G0/G1 of treated Bcap-37.

\section{Immunofluorescence assay of mitochondrial membrane potential in Bcap-37 cells}

The loss of mitochondrial membrane potential was one of the typical characteristics of apoptosis [30]. In this study, the change of mitochondrial membrane potential in Bcap-37 cells treated with TAT-Survivin(T34/117A), TATBIR(T34A), and TAT-CC(T117A) for $48 \mathrm{~h}$ was detected using Rhodamine 123 and Hoechst33342 staining. The intensity of green fluorescence in TAT-BIR(T34A)and TAT-Survivin(T34/117A)-treated group decreased drastically compared with that of control group, and even no green fluorescence was seen in some cells. However, the intensity of green fluorescence in TAT-CC(T117A)treated group was not significant (Figure 7). These phenomena suggested that the mitochondria was not stained by Rhodamine 123 due to lowered mitochondrial membrane potential in Bcap-37 cells treated with TATBIR(T34A) and TAT-Survivin(T34/117A). In other words, TAT-BIR(T34A) promoted the apoptosis of Bcap-37 cells by interfering the membrane potential of the mitochondria, and further the normal functions of mitochondria. 


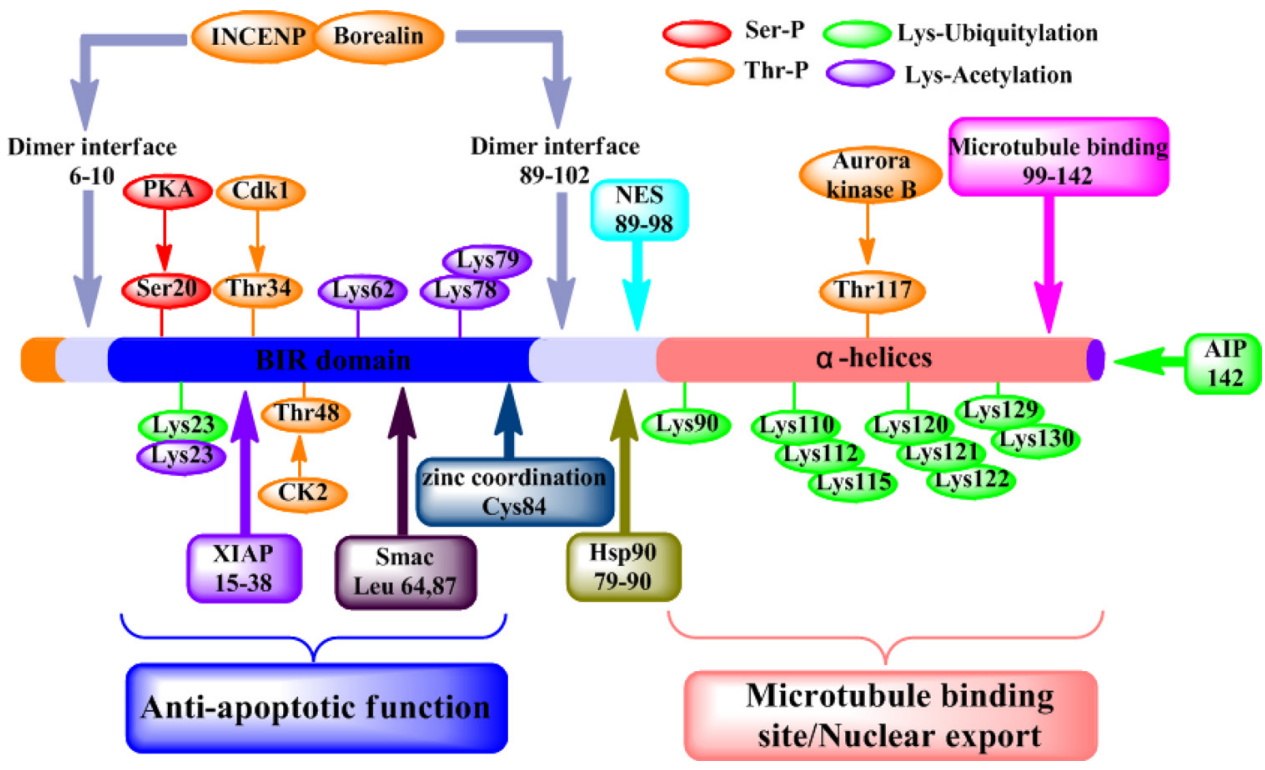

Figure 1: Structure and function of survivin protein. Various functional motifs in survivin are indicated, including the binding sites for protein partners, dimer interface (residues 6-10 and 89-102), XIAP (residues 15-38), Smac (residues 64 and 87 ), Hsp90 (residues 79-90), nuclear export sequence (NES) (residues 89-98), polymerized microtubules (residues 99-142) and AIP (residue 142). And the position of experimentally validated phosphorylation sites for PKA (Ser20) p34cdc2/Cdk1 (Thr34) and Aurora B (Thr117). Residues involved in the $\mathrm{Zn}^{2+}$ coordination sphere (Cys84), Ser/Thr phosphorylation, acetylation or ubiquitylation.
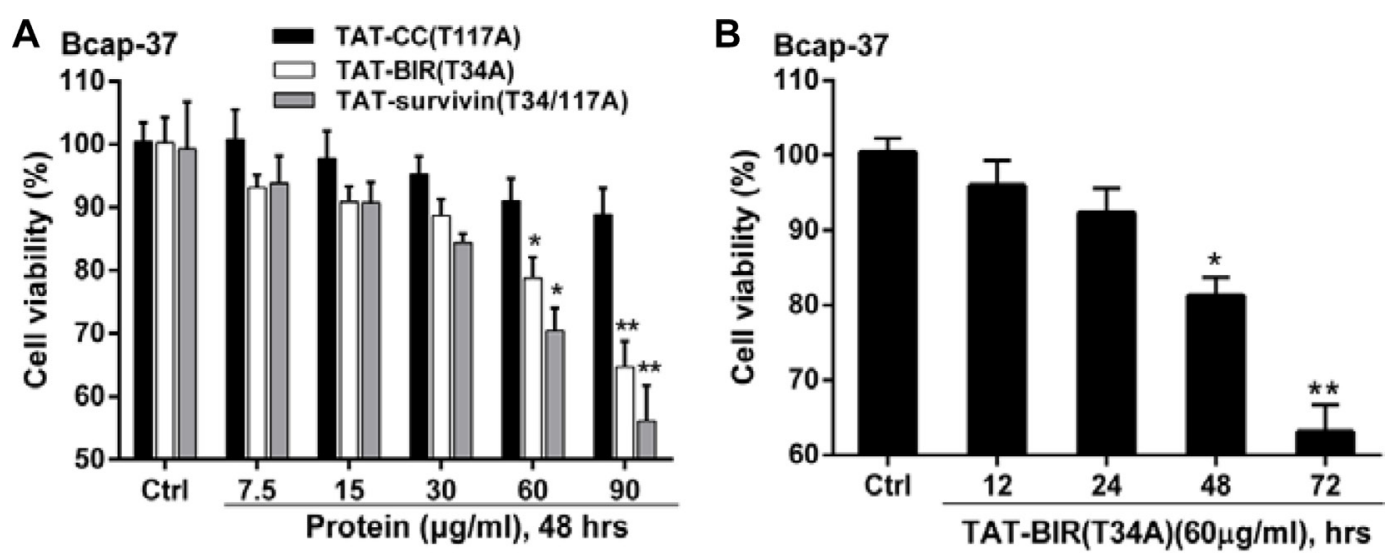

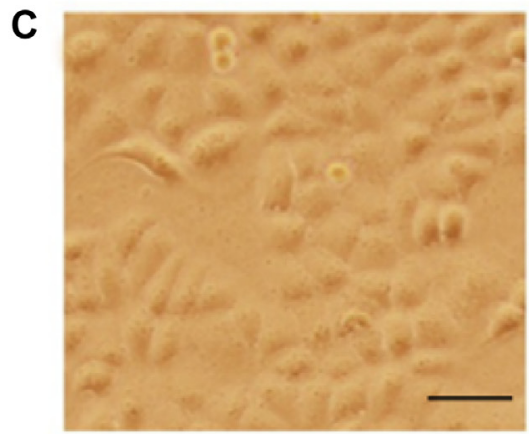

Control

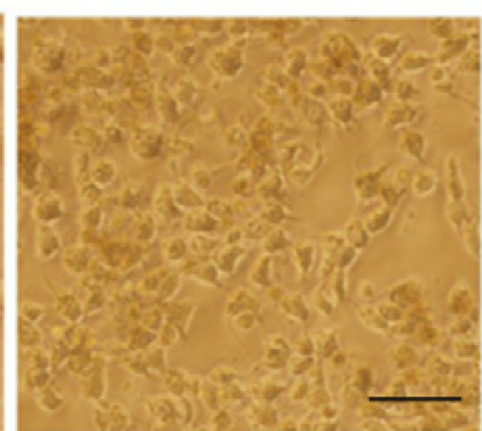

TAT-BIR(T34A)

Figure 2: TAT-BIR(T34A) inhibit proliferation in Bcap-37 cells. (A) Viability of Bcap-37 cells after treated with recombinant proteins (TAT-Survivin(T34/117A), TAT-BIR(T34A), and TAT-CC(T117A)). Bcap-37 cells were exposed to recombinant proteins at a various concentrations $(7.5,15,30,60$, and $90 \mu \mathrm{g} / \mathrm{mL})$ for $48 \mathrm{~h}$; cell viability was measured by MTT assay. The data presented was means \pm SD of 3 independent experiments. ${ }^{*} P<0.05$ and ${ }^{* *} P<0.01$ compared with the control group. (B) Viability of Bcap-37 cells treated with $60 \mu \mathrm{g} / \mathrm{mL}$ TAT-BIR(T34A) for different time $(12,24,48$ and 72 hours). The cell viability was measured by MTT assay. Data represented was the means $\pm \mathrm{SD}$ of three independent experiments. ${ }^{*} P<0.05$ and ${ }^{* *} P<0.01$ compared with the control group. (C) The morphological change of Bcap-37 cells treated with $60 \mu \mathrm{g} / \mathrm{mL}$ TAT-BIR(T34A) for $24 \mathrm{~h}$. $(\mathrm{Ba} \mathrm{r}=50 \mu \mathrm{m})$ 


\section{Immunofluorescence for localization of recombinant proteins in Bcap-37 cells}

In order to observe the localization of recombinant proteins, Bcap-37 cells were treated with enhanced green fluorescent protein (EGFP) conjugated TAT-CC(T117A) (namely TAT-CC-EGFP) for $48 \mathrm{~h}$. We firstly assayed the penetrating ability of recombinant proteins with TAT peptide into cells by detecting the proportion of fluorescent protein with flow cytometry. The cells with green fluorescence accounted for $2.9 \%, 11.1 \%$, and $26.2 \%$, after incubated with TAT-CC-EGFP for different period of time ( $3 \mathrm{~h}, 6 \mathrm{~h}$, and $9 \mathrm{~h}$ ) (Figure $8 \mathrm{~A})$, respectively. It exhibited that TAT-CC(T117A) protein had a higher penetrating efficiency, the result was consistent with Cho et al. [31]. Furthermore, TAT-CC-EGFP was able to enter cells, abounded in the cells, and appeared green, whereas tubulin was red, and superimposed with green (Figure 8B). These results indicated that $\mathrm{CC}$ domain of survivin could bind with tubulin, and localize in microtubules, suggesting $\mathrm{CC}$ domain of survivin might associate with microtubules of the mitotic spindle at the beginning of mitosis, and regulate microtubule dynamics.

\section{Autophagy of Bcap-37 cells treated with recombinant proteins}

Acridine orange was a kind of cell-permeable fluorescent dye, and dyed cytoplasm and DNA bright green [32]. Meanwhile, it could penetrate into acidic organelles, such as autophagy-lysosome, and showed red fluorescence in lower $\mathrm{pH}$, and the intensity was related
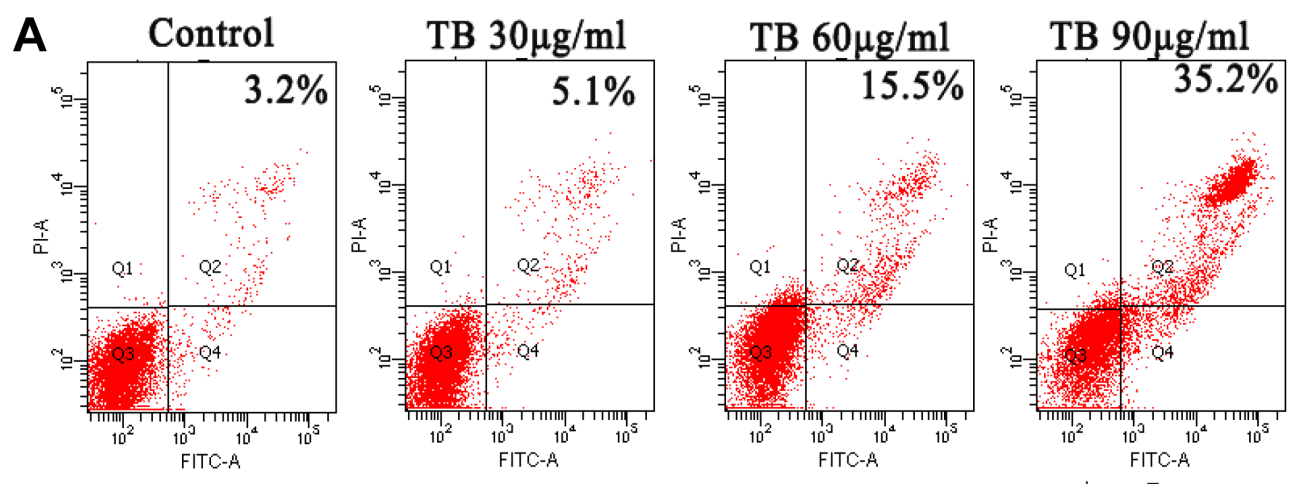

\section{$36 \mathrm{~h}$}
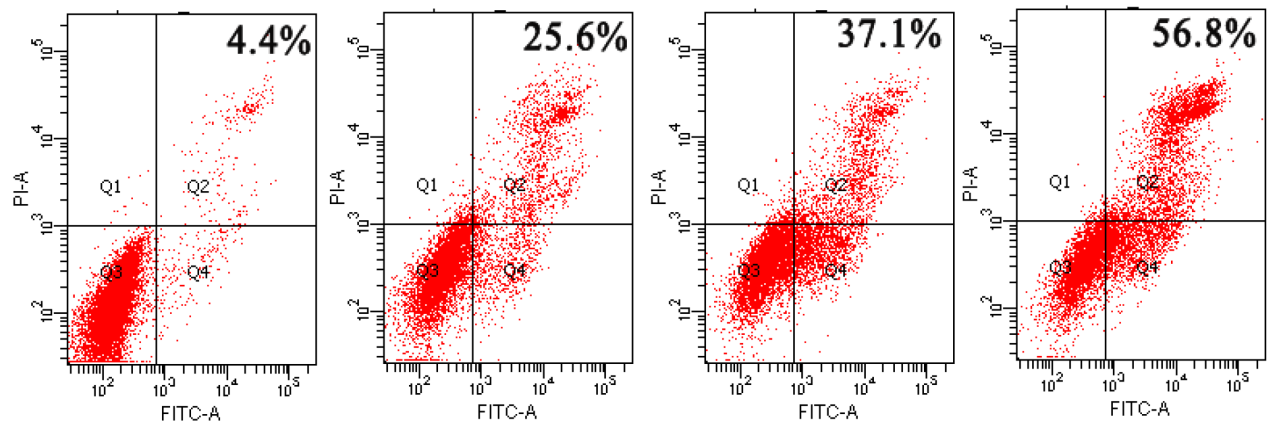

\section{$60 \mathrm{~h}$}

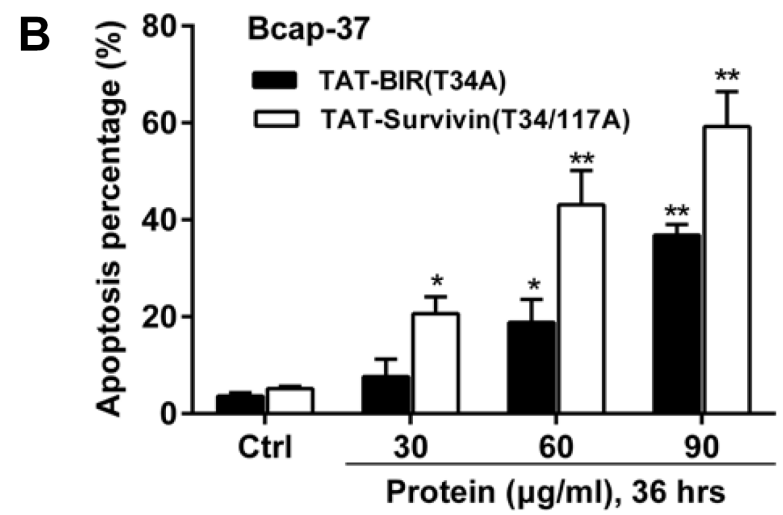

Figure 3: Apoptosis of Bcap-37 cells was analyzed by flow cytometry. (A) Apoptosis assay of Bcap-37 incubated with different concentration $(30,60$, and $90 \mu \mathrm{g} / \mathrm{mL})$ of TAT-BIR(T34A) for $36 \mathrm{~h}$ or $60 \mathrm{~h}$. (B) Apoptosis analysis of cells treated with different concentration $(30,60$, and $90 \mu \mathrm{g} / \mathrm{mL})$ of TAT-BIR(T34A) or TAT-Survivin(T34/117A) for $36 \mathrm{~h}$. The apoptosis percentage was the means \pm SD of 3 independent experiments. ${ }^{*} P<0.05$ and ${ }^{* *} P<0.01$ compared with the control group. 


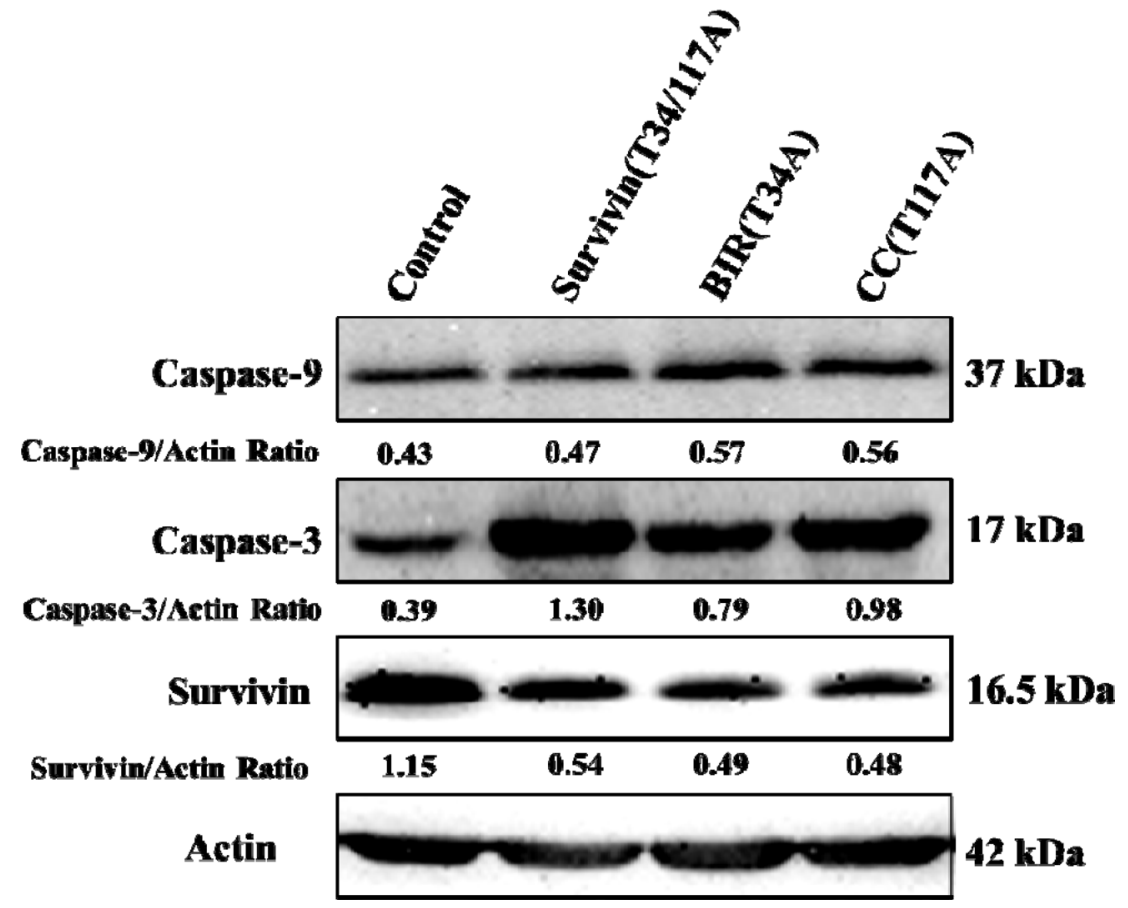

Figure 4: Western blot analysis of apoptosis-related proteins. Activated caspase-9, activated caspase-3, and survivin were detected by western blot with cellular extracts of Bcap- 37 cells treated with each of the three kinds of proteins for $48 \mathrm{~h}$. Actin was used to confirm equal protein loading on the gel and to show the relative purity. The grey value of protein bands have been quantified by Image J.

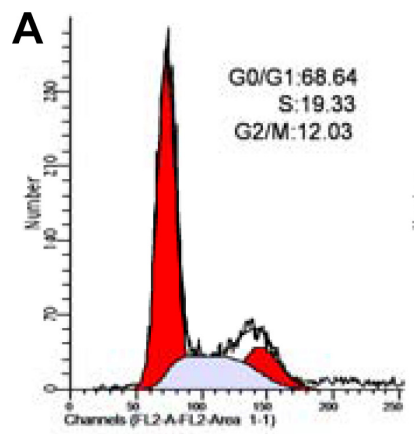

Control

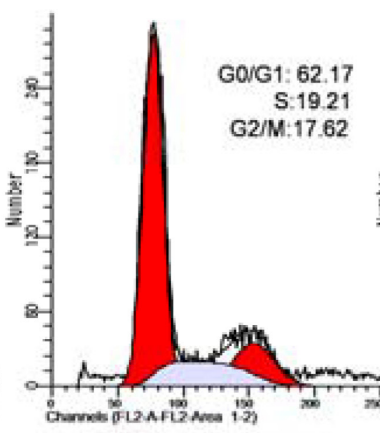

TAT-BIR(T34A)

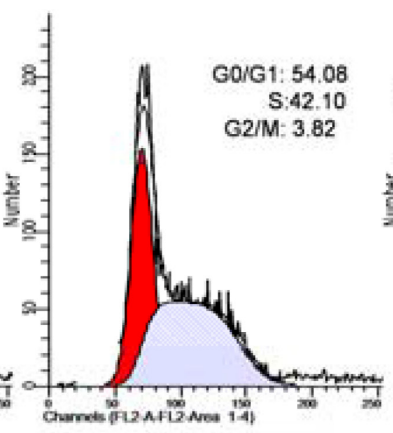

TAT-CC(T117A)

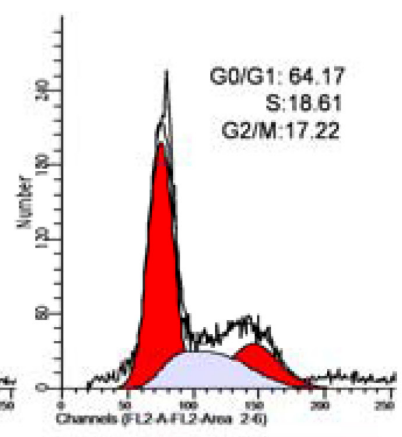

TAT-Survivin(T34/117A)

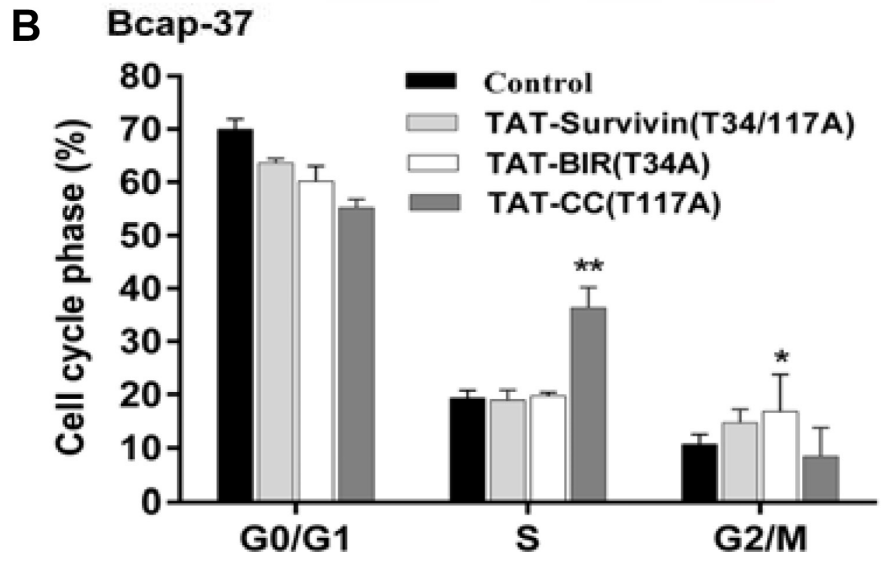

Figure 5: Cell cycle distribution of Bcap-37 treated with different proteins. Bcap-37 cells were treated with $30 \mu \mathrm{g} / \mathrm{mL}$ TAT-BIR(T34A), TAT-CC(T117A), and TAT-Survivin(T34/117A) for $48 \mathrm{~h}$. The cells were fixed by ice-cold 70\% (v/v) ethanol, stained with $50 \mu \mathrm{g} / \mathrm{mL}$ PI, and analyzed by flow cytometry. (A) Cell cycle distribution analyzed by flow cytometry. (B) Histogram of cell cycle distribution of Bcap-37 cells incubated with three kinds of protein. The data presented are the means \pm SD of 3 independent experiments. ${ }^{*} P<0.05$ and ${ }^{* *} P<0.01$ compared with the control group. 
to the degree of acidity [33]. After stained with acridine orange, cell nucleus of the control group appeared green, suggesting there was no detective acidic organelles, such as autophagy-lysosome. However, the intensity of red fluorescence increased in the cytoplasm of Bcap37 cells treated with TAT-Survivin(T34/117A), TATBIR(T34A), and TAT-CC(T117A) for 48h, and emerged yellow after superimposed green (Figure 9), indicating acidic organelles increased in the treated group. It was noteworthy that intracellular acidic organelles increased more in the Bcap-37 cells treated with TAT-CC(T117A) and TAT-Survivin(T34/117A) than that in the group treated with TAT-BIR(T34A). It also implied that TATCC(T117A) might promote autophagy.
At the same time, in this study, LC3B protein, one of the light chain 3(LC3) members characterizing the autophagy, was detected with LC3B antibody in Bcap-37 cells incubated with TAT-BIR(T34A), TAT-CC(T117A), and TAT-Survivin(T34/117A) for $48 \mathrm{~h}$. The level of LC3B protein increased slightly in Bcap-37 cells treated with TAT-BIR(T34A). However, it increased significantly in Bcap-37 cells incubated with TAT-CC(T117A) and TATSurvivin(T34/117A) (Figure 10). Western blot identified that the expression of LC3B in TAT-CC(T117A)-treated group was highest, and was about 2.35-fold of that in the control group by quantification (Figure 6). It was exciting that TAT-CC(T117A) treatment leaded to the highest level of autophagy of Bcap-37 cells, which

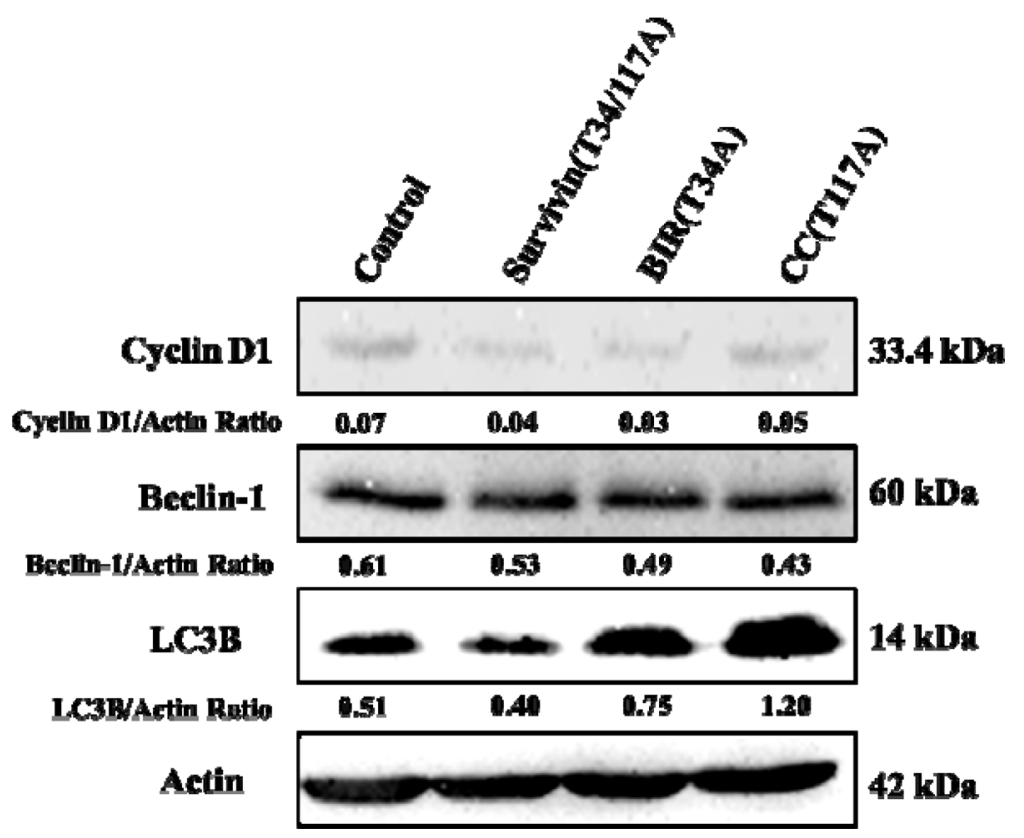

Figure 6: Western blot analysis for the activation of autophagy- and cell cycle-related proteins. The Bcap-37 cells were incubated with three kinds of recombinant proteins for $48 \mathrm{~h}$, and their cellular extracts were detected by western blot for Cyclin D1, Beclin-1, and LC3B. Actin was used to indicate comparable amount of protein loading on the gel. The grey value of protein bands have been quantified by Image $\mathrm{J}$.

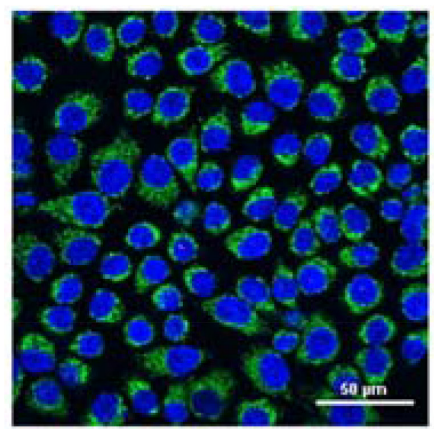

Control

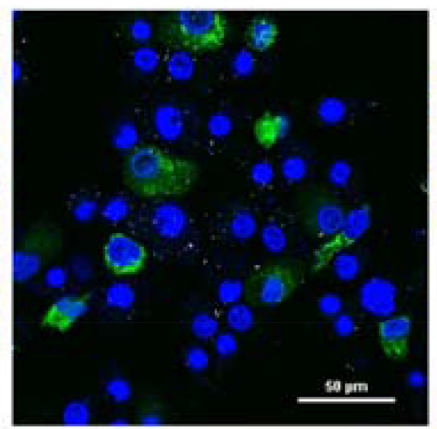

TAT-BIR(T34A)

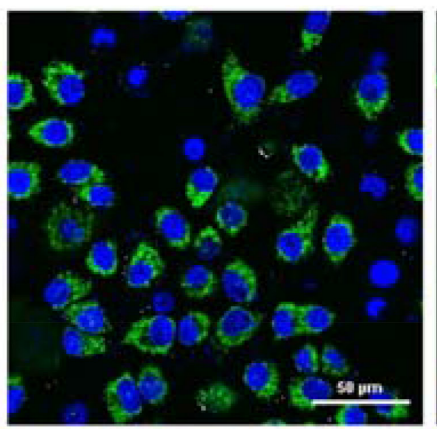

TAT-CC(T117A)

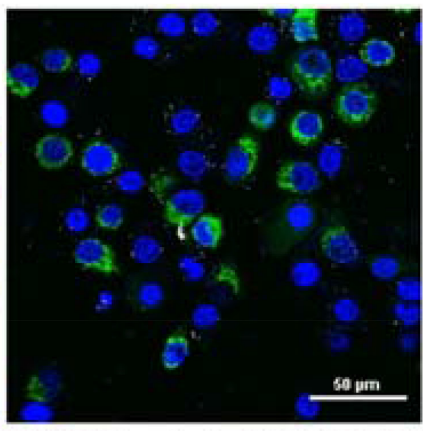

TAT-Survivin(T34/117A)

Figure 7: The change of mitochondrial membrane potential of Bcap-37 cells. The Bcap-37 cells after incubated with TATBIR(T34A), TAT-CC(T117A), and TAT-Survivin(T34/117A) for $48 \mathrm{~h}$ were placed in confocal laser scanning microscopy to observe cell fluorescence. The change of mitochondrial membrane potential was detected using Rhodamine 123 and Hoechst33342 staining. Rhodamine 123 could enter mitochondrial matrix and appeared green, while Hoechst33342 would stain mitochondrial DNA blue. The intensity of green fluorescence illustrated the membrane potential. (Bar $=50 \mu \mathrm{m})$ 
was consistent with the result of immunofluorescence, indicating TAT-CC(T117A) could promote autophagy. Moreover, Beclin-1 was the only tumor suppressor gene that had been confirmed to associate with autophagy in mammals [34]. Western blot evaluated that the expression of Beclin-1 in TAT-BIR(T34A)-, TAT-CC(T117A)-, and TAT-Survivin(T34/117A)-treated group was slightly lower than the control group, while the expression of Beclin-1 in TAT-CC(T117A)-treated group was higher than TATBIR(T34A)- and TAT-Survivin(T34/117A)-treated group (Figure 6), suggesting TAT-CC(T117A) could promote autophagy by increased the level of Beclin-1.

\section{DISCUSSION}

The multifunction of survivin in apoptosis, cell cycle, and autophagy had been reported in recent years $[35,36]$. However, the specific function of two different domains of survivin in these functions was unclear. After separated two structures (BIR domain and CC domain) of full-length survivin, our results confirmed that a single BIR domain (T34A) structure still had the ability to inhibit proliferation of cancer cell, while CC domain (T117A) had little effect on cell proliferation (Figure 2A). Moreover, TAT-BIR(T34A) could inhibit growth of Bcap-37 cells
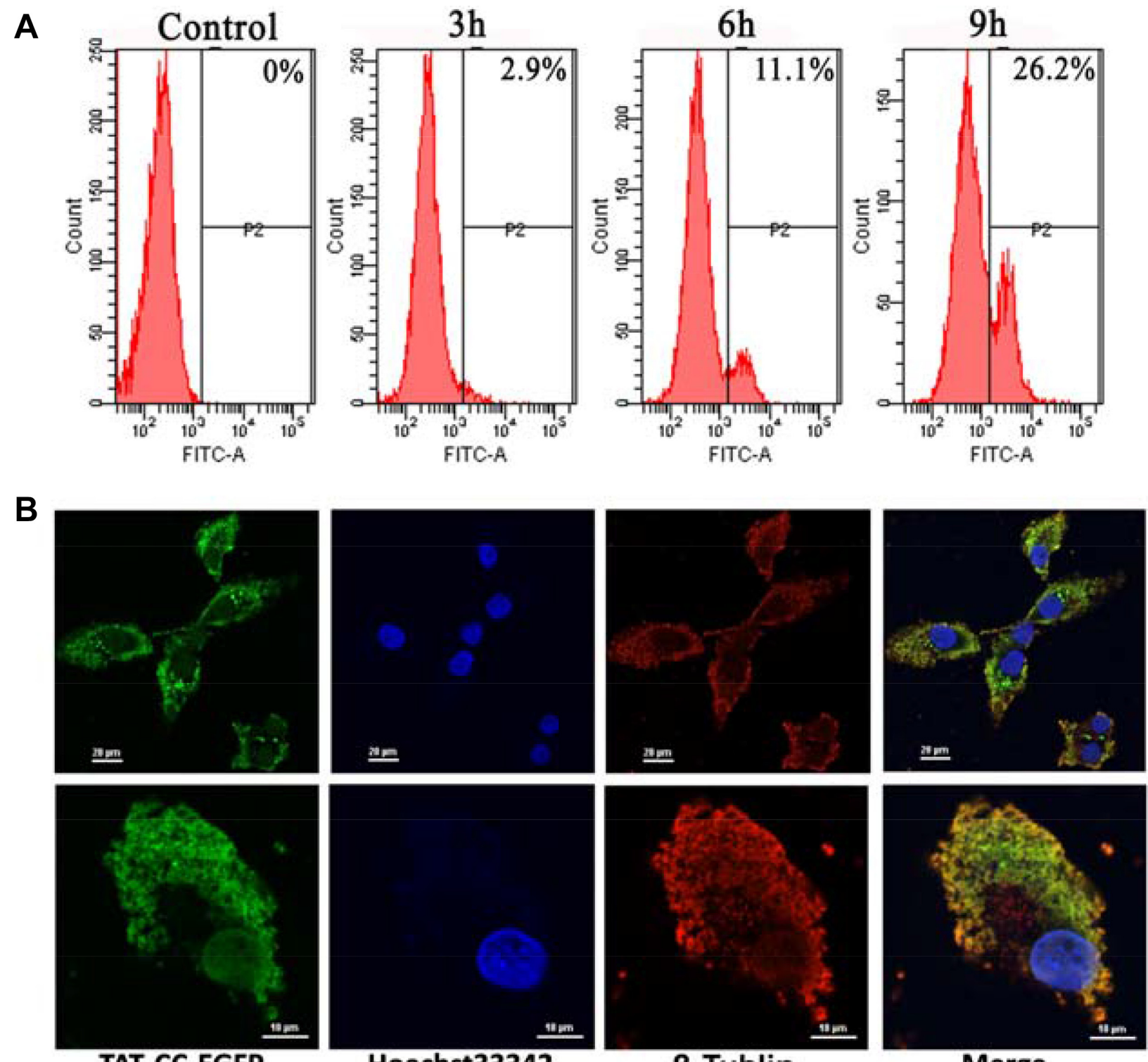

TAT-CC-EGFP

Hoechst33342

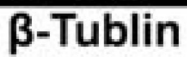

Merge

Figure 8: Cellular entry and location of TAT-CC-EGFP. (A) Cellular entry of TAT-CC-EGFP determined by flow cytometry. The cell was treated with TAT-CC-EGFP for different time points ( $3 \mathrm{~h}, 6 \mathrm{~h}$, and $9 \mathrm{~h}$ ), and analyzed by flow cytometry. (B) The localization of TAT-CC-EGFP in Bcap-37 cells. Bcap-37 cells were incubated with TAT-CC-EGFP for $48 \mathrm{~h}$, fixed by $4 \%$ (v/v) paraformaldehyde (PA), then treated by $0.1 \%(\mathrm{v} / \mathrm{v})$ Triton X-100, and blocked for $1 \mathrm{~h}$ at room temperature with $3 \%$ BSA. Tubulin was probed for monoclonal antibody against tubulin followed by cy3-conjugated goat anti-rabbit secondary antibody. TAT-CC-EGFP entered cells and appeared green. DNA dyed by Hoechst33342 was blue. Tubulin was red. $(\mathrm{Up}$, bar $=20 \mu \mathrm{m}$; down, bar $=10 \mu \mathrm{m})$ 
and induce apoptosis in a dose- and time-dependent manner (Figure 2 and Figure 3A). The difference on cell proliferation and apoptosis implied that the pro-apoptotic domain mutant of survivin existed in BIR domain mutant (BIR(T34A)) rather than CC domain mutant (CC(T117A)). Our previous studies also found that TAT-Survivin(T34A) inhibited proliferation of Bcap-37 cells, whereas TATSurvivin(T117A) had little effect on cell proliferation [27]. As previously reported, because its BIR motif, survivin was a potential member of the inhibitor of apoptosis (IAP) family of proteins, which acted at discrete steps to regulate the apoptotic pathway of cell death [3]. Phosphorylation at threonine 34, within its BIR domain, by Cdk1 was critical to anti-apoptotic roles of survivin. Further studies have found that the non-phosphorylatable form, survivinT34A, accelerated cell proliferation and promoted apoptosis, whereas survivinT34E retarded growth and promoted survival [37]. Surprisingly, we observed that the effect of pro-apoptosis of single BIR(T34A) was much weaker than full-length Survivin(T34/117A) (Figure 3B). As previously described, dimer interface included the 6-10 residues of $\mathrm{N}$-terminal and the 14 residues (survivin 89102 ) in the connecting region between the BIR domain and the C-terminal $\alpha$-helix structure [9]. Because TATSurvivin(T34/117A) possessed complete amino acids of dimer interface compared to TAT-BIR(T34A), TATSurvivin(T34/117A) bound more wild-type survivin than TAT-BIR(T34A), leading to higher apoptosis rate of
Bcap-37 cells. Moreover, the effect of pro-apoptosis of full-length Survivin(T34/117A) was much stronger than full-length Survivin(T34A) [27], which also eliminated the effect of the CC domain on apoptosis. There are two main pathways of apoptosis in mammals, namely endogenous (mitochondrial pathway) and exogenous pathways [3]. In order to further determine the main apoptotic pathway of Bcap-37 cells induced by BIR domain mutant, the expression of apoptosis-associated proteins and mitochondrial membrane potential were analyzed by western blot and immunofluorescence. Western blot discovered that pro-apoptosis associated proteins activated caspase- 9 and caspase- 3 increased, whereas anti-apoptosis associated proteins survivin decreased (Figure 4). Survivin inhibited activation of procaspase- 9 by interfering with the apoptosome formation. Active caspase-9, however, activated effector caspases-3 and caspases-7, which in turn induced apoptosis [21]. In vitro study indicated that Thr34 phosphorylation of survivin by $\mathrm{CDC} 2$ was essential for the interaction of survivin with caspase-3, 7 and 9 [20]. It demonstrated that single BIR(T34A) was heterologous to wild-type survivin, which resulted in the ubiquitin-dependent degradation of survivin, prevented wild-type survivin from interacting directly with caspase-3, and prompted survivin decreased and caspase-3 increased. Mitochondrial dysfunction was often related to the loss of mitochondrial membrane potential (MMP) and the release of cytochrome [38]. Our studies ascertained that TAT-BIR(T34A) promoted the
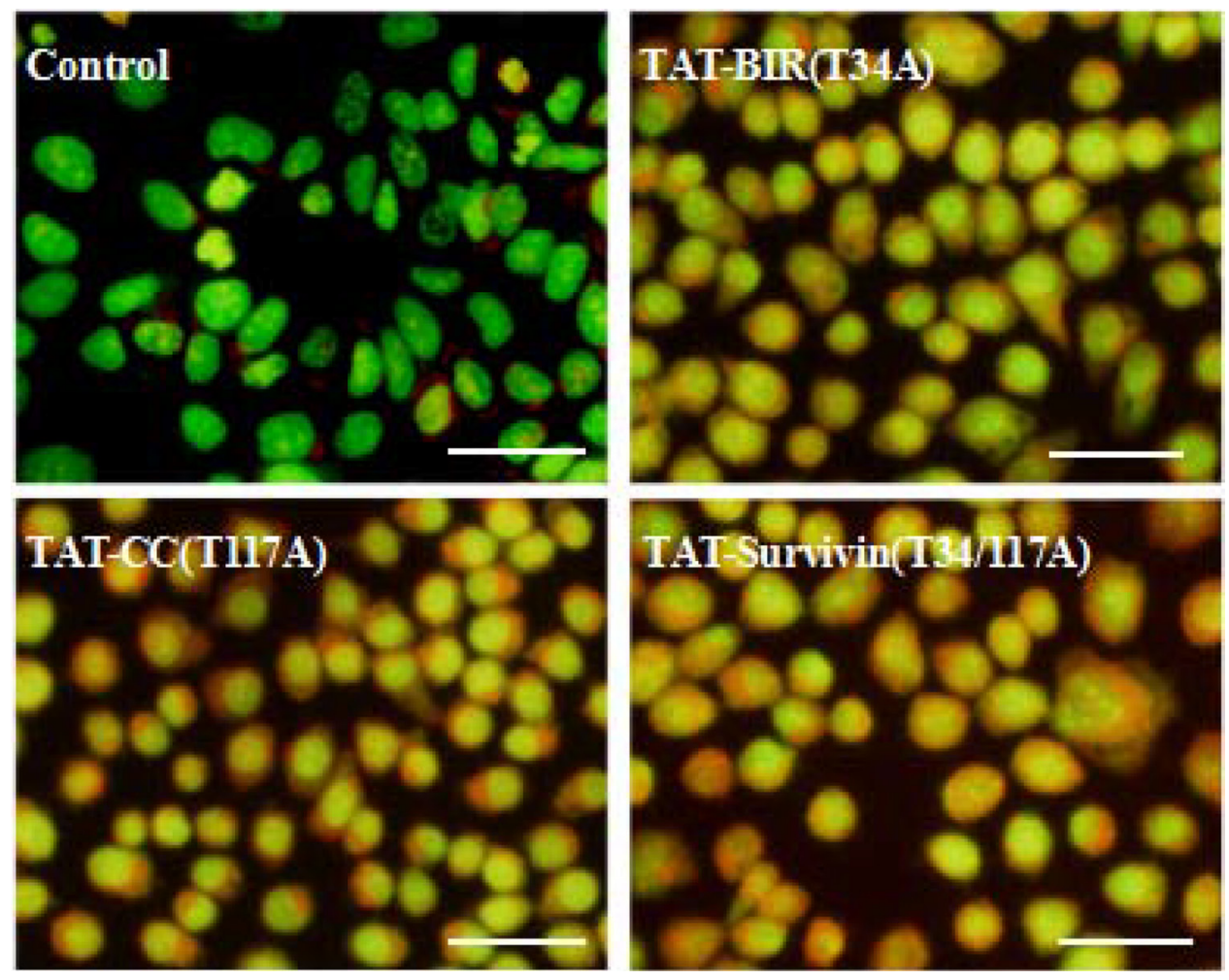

Figure 9: Detection of autophagy of treated Bcap-37 cells using acridine orange staining. Bcap- 37 cells $\left(2 \times 10^{4}\right.$ cells/well $)$ were seeded into 6-well plate overnight, and then treated with TAT-BIR(T34A), TAT-CC(T117A), and TAT-Survivin(T34/117A) for 48 h. The harvested cells were stained with acridine orange, and the fluorescence was observed with microscopy. $(\mathrm{Bar}=50 \mu \mathrm{m})$ 
apoptosis of Bcap-37 cells by interfering the membrane potential of mitochondria. Some studies have found that a mutation of Survivin(T34A) could induce the release of cytochrome $\mathrm{c}$ from the mitochondria, and caused apoptosis [21]. For that reason, these data suggested that BIR domain mutant (BIR(T34A)) inhibited cell proliferation and induced caspase-dependent apoptosis via the mitochondrial pathway.

Survivin mRNA expression is regulated by the cell cycle, and it peaks in the G2/M phase and rapidly declines in the G1 phase [39]. Furthermore, overexpression of survivin can accelerate $\mathrm{S}$ phase shift through a mechanism involving interaction with CDK4, counteract G1 arrest, and result in phosphorylation of retinoblastoma protein (Rb), a tumor suppressor protein [40]. Barrett et al. [37] discovered that the cell cycle profile of T34A-treated cells was normal, whereas T34E-treated cells had a significantly increased $\mathrm{G} 2 / \mathrm{M}$ population, suggesting that phosphorylated Thr34 inhibits mitosis. On the contrary, our previous experiments found that non-phosphorylatable survivin mutants Survivin(T34A) and Survivin(T34/117A) arrested cell in $\mathrm{G} 2 / \mathrm{M}$ phase. Based on this contradiction, we discovered TAT-BIR(T34A) abolished kinase p34 ${ }^{\text {cdc2 }}$ cyclin B1 on the survivin phosphorylation, and disrupted the biological function of wild-type survivin, leading to obvious cell cycle arrested at G2/M phase (Figure 5A and B), which might cause failure of cell division. In addition, survivin could also promote mitosis by forming the chromosomal passenger complex (CPC) with Aurora-B kinase, inner centromere protein (INCENP), and Borealin [41]. It localized to the spindle microtubule organizing center (MTOC) during the G2/M phase of cell cycle and regulated microtubule dynamics by a direct association with polymerized tubulin [14]. Meanwhile, survivin was phosphorylated by Aurora-B kinase at threonine 117 in its alpha helical coil, which regulated the entire chromosomal passenger complex in mammals [10]. In this study, TAT-CC(T117A) showed the different functions that TAT-CC(T117A) treatment enabled the proportion of cells in G0/G1 phase decreased sharply, and proportion of cells in $\mathrm{S}$ phase increased significantly (Figure 5A and 5B). Because Cyclin D1 was first synthesized in cell cycle and peaked at mid-G1 phase [40], the Cyclin D1 level of TAT-CC(T117A)-treated group by western blot was higher than that in TAT-BIR(T34A) group and TAT-Survivin(T34/117A) group (Figure 6). Emerging
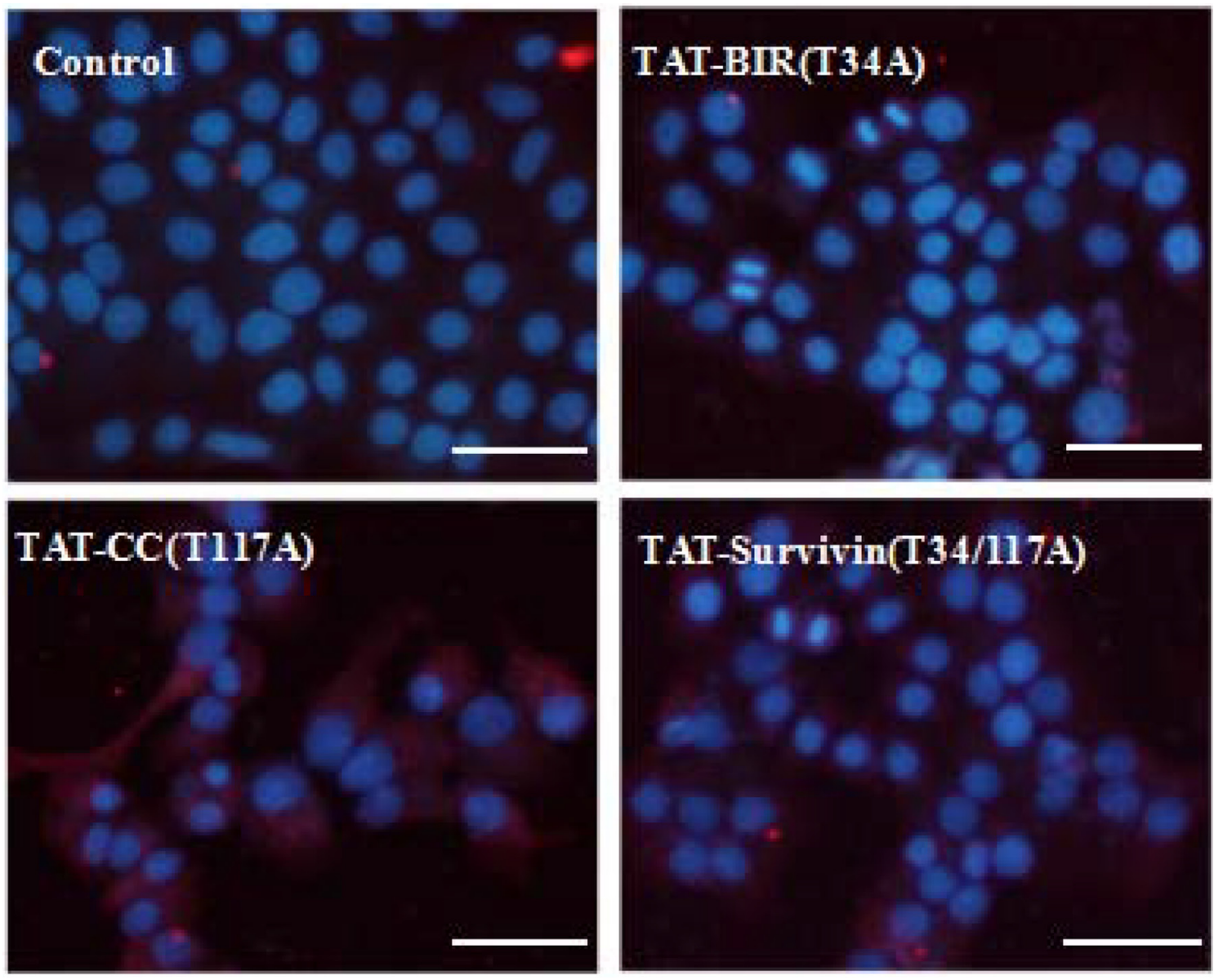

Figure 10: Detection of LC3B in treated Bcap-37 cells using immunofluorescence assay. After incubated with TATBIR(T34A), TAT-CC(T117A), and TAT-Survivin(T34/117A) for $48 \mathrm{~h}$, LC3B protein of Bcap-37 cells was detected with LC3B antibody which displayed cy3-marked fluorescent secondary antibodies, showing red. Nuclear DNA dyed by Hoechst33342 was blue. (Bar $=50 \mu \mathrm{m})$. 
data supported the notion that TAT-CC(T117A) promoted Bcap-37 cells to leave the G0/G1 resting phase and to enter the stage of DNA replication, and thus promoting cell division. Moreover, we constructed TAT-CC-EGFP to observed localization of recombinant protein in Bcap-37 cells, and demonstrated that $\mathrm{CC}$ domain of survivin was able to bind with tubulin, and localize in microtubules (Figure 8B), indicating that the function of $\mathrm{CC}$ domain at cell division to control microtubule stability and assembly of a normal mitotic spindle. It was interesting to note that TAT-BIR(T34A) blocked mitosis, while TAT-CC(T117A) promoted process of DNA replication and mitosis.

Autophagy was the two-blade sword that low levels of autophagy were a cytoprotective mechanism, but excessive and continuous autophagy would cause cancer cell death [42]. It was reported YM155, survivin inhibitor induced apoptosis of depended autophagy in prostate cancer cells [43]. Wang et al. [25] also found that suppression of survivin by YM155 induced autophagydependent apoptosis, and YM155-induced autophagy played a pro-apoptotic role. According to the result of these previous experiments, we conjectured that upregulation of survivin inhibited autophagy, whereas down-regulation of survivin promoted autophagy. We mentioned before, single BIR(T34A) was heterologous to wild-type survivin and resulted in the ubiquitin-dependent degradation of survivin, which might be the main cause of survivin to promote autophagy. Based on this idea, we used acridine orange to firstly stain Bcap-37 cells which treated with recombinant proteins. Acridine orange could penetrate into autophagy vacuoles, and emitted red fluorescence in lower $\mathrm{pH}$, and the intensity was related to the degree of acidity [33]. We discovered red fluorescence representing acidic organelle in Bcap-37 cells of TATSurvivin(T34/117A)- and TAT-CC(T117A)-treated group were dramatically deepened, while fluorescence intensity of TAT-BIR(T34A) group was relatively weak (Figure 9). Therefore, it could speculate that TAT-CC(T117A) might promote autophagy. In addition, LC3B protein was one of microtubule-associated protein 1 light chain 3 (LC3) members characterizing the autophagy, and the levels of LC3B to some extent reflected the number of autophagy body [44, 45]. Immunofluorescence assay discovered intracellular LC3B protein content increased slightly in Bcap-37 cells treated with TAT-BIR(T34A), whereas the levels of LC3B protein increased significantly incubated with TAT-CC(T117A) and TAT-Survivin(T34/117A) (Figure 10), suggesting TAT-CC(T117A) could promote the formation of autophagy vacuoles. Western blot also further yielded similar results, the expression level of LC3B was remarkable higher in Bcap-37 cell incubated with TAT-CC(T117A) than that of other groups (Figure 6). Beclin-1 was a protein that plays a central role in autophagy, and interacted with multiple cofactors (Atg14L, UVRAG, Bif-1, Rubicon, Ambra1, HMGB1, IP3R, PINK, and survivin) to promote the formation of the Beclin-1-Vps34-Vps15 complex which triggered the autophagy protein cascade [46]. The interaction of autophagic governor Beclin-1 and survivin could respond to TRAIL in human glioma cells [24]. The expression of Beclin-1 in TAT-CC(T117A)-treated group was higher than TAT-BIR(T34A)- and TAT-Survivin(T34/117A)treated group by western blot (Figure 6), suggesting TAT-CC(T117A) could promote autophagy by increased the level of Beclin-1. Therefore, we demonstrated that $\mathrm{CC}$ domain of survivin was the main cause of survivin to promote autophagy. The specific mechanism of CC domain of survivin to promote autophagy, however, required further study. Recent research found that Beclin-1 was a direct substrate of caspase-3, caspase-7 and caspase- 8 in apoptosis, and the caspase cleavage of Beclin-1 was sufficient to suppress autophagy [23]. TAT-BIR(T34A) and TAT-Survivin(T34/117A) prompted caspase-3 increased and survivin decreased, which caused cleavage of Beclin-1 and inhibited the formation of the Beclin-1-Vps34-Vps15 complex that triggered the autophagy protein cascade. Therefore, BIR domain mutant (BIR(T34A)) slightly promoted autophagy via the caspase-dependent apoptosis, but molecular details of these interactions are poorly understood.

In summary, single BIR domain and $\mathrm{CC}$ domain of survivin had showed some functions. Further experiments confirmed that TAT-BIR (T34A) could be used to inhibit cell proliferation, promote apoptosis, and block mitosis, and TAT-CC (T117A) showed mainly to promote autophagy, process of DNA replication, and mitosis to breast cancer cells. Maybe the full-length survivin displayed the functions in the anti-apoptosis, regulating cell cycle, and promoting autophagy by two different domain of survivin. This will lay the foundation for interpreting the multifunction mechanism of survivin in cell fates, and further make senses in the study of cancer pathophysiology, drug discovery, and medical diagnosis targeting survivin precisely and efficiently.

\section{MATERIALS AND METHODS}

\section{Cell lines and culture conditions}

Human breast cell lines Bcap-37 was cultured in Dulbecco's Modified Eagle Medium (DMEM, Gibco, USA) supplemented with $10 \%(\mathrm{v} / \mathrm{v})$ fetal bovine serum (FBS, Gibco, USA), $100 \mu \mathrm{g} / \mathrm{mL}$ streptomycin, and 100 unit $/ \mathrm{mL}$ penicillin. Cells were incubated at $37^{\circ} \mathrm{C}$ with $5 \%$ $\mathrm{CO}_{2}$ supply.

\section{Construction and expression of the recombinant proteins}

In order to study the function(s) of each domain of survivin, we used mutant protein TAT-Survivin(T34/117A) (full-length survivin with mutations at T34A and T117A) 
as a reference. On this basis, we constructed the truncated version of the full-length protein (namely BIR(T34A) and $\mathrm{CC}(\mathrm{T} 117 \mathrm{~A})$ ), fused with penetrating peptide TAT. In addition, the EGFP-tagged proteins were constructed for the purpose of transmembrane efficiency determination and localization.

\section{Morphology and cell viability assay}

Bcap-37 cells in 96-well plate $\left(2 \times 10^{4}\right.$ cells/well $)$ were divided into two groups, control group and treatment group. The cells in treatment group were incubated with different concentrations $(7.5,15,30,60$, and $90 \mu \mathrm{g} /$ $\mathrm{mL}$ ) of TAT-BIR(T34A), TAT-CC(T117A), and TATSurvivin(T34/117A), respectively. The control cells were incubated with phosphate buffer solution (PBS buffer). After incubation for $48 \mathrm{~h}$, the supernatant was cleaned away, 180 $\mu \mathrm{L}$ medium and $20 \mu \mathrm{L}$ MTT (Solarbio, China) solution (5 $\mathrm{mg} / \mathrm{mL}$ ) were added and incubated for $4 \mathrm{~h}$. After incubated for $4 \mathrm{~h}$, MTT-containing medium was removed, and 150 $\mu \mathrm{L}$ DMSO was added to each well to dissolve formazan. The optical densities of the samples were determined by a spectrophotometer (Bio-Tek, USA) at $490 \mathrm{~nm}$. Each experiment was performed independently for three times. Morphologic analysis was performed followed by the treatment of Bcap-37 cells with TAT-BIR(T34A) for $48 \mathrm{~h}$.

\section{Localization of recombinant proteins and assay of mitochondrial membrane potential}

Bcap-37 cells $\left(2 \times 10^{4}\right.$ cells/well $)$ were seeded in confocal petri dish (NEST, China), and incubated at $37^{\circ} \mathrm{C}$ with $5 \% \mathrm{CO}_{2}$ supply for overnight. The adhered cells were treated with TAT-CC-EGFP for $48 \mathrm{~h}$. After the supernatant was cleared away, the cells were fixed by $4 \%(\mathrm{v} / \mathrm{v})$ paraformaldehyde (PA) for $10 \mathrm{~min}$, and then washed three with PBS. Treatment by $0.1 \%(\mathrm{v} / \mathrm{v})$ Triton X-100 was done at room temperature for $10 \mathrm{~min}$. The cells were blocked for $1 \mathrm{~h}$ at room temperature with $3 \%$ BSA after cell permeabilization. Incubation with monoclonal antibody against $\beta$-tublin was $10 \mathrm{~min}$ at room temperature. After the washing steps with PBS, incubation with the secondary anti- $\beta$-tublin-cy 3 was carried out in the dark for $1 \mathrm{~h}$. Finally, the Bcap-37 cells were washed with PBS, and stained with Hoechst33342 for $10 \mathrm{~min}$ in the dark. The cell fluorescence was recorded with a confocal laser scanning microscopy (Nikon, Japan). For mitochondrial membrane potential assay, Bcap-37 cells were treated by TAT-Survivin(T34/117A), TAT-BIR(T34A), and TAT-CC(T117A) for $48 \mathrm{~h}$, and then were stained with Rhodamine 123 by following the instructed protocols.

\section{Cell cycle and apoptosis assay}

Bcap-37 cells $\left(2 \times 10^{4}\right.$ cells/well $)$ were seeded into 6-well plate (Corning, Elmira, NY) overnight. The cells of apoptosis assay were treated with different concentrations (30, 60 and $90 \mu \mathrm{g} / \mathrm{mL}$, respectively) of TAT-BIR(T34A) for $36 \mathrm{~h}$ or $60 \mathrm{~h}$, then the cells were harvested by centrifugation at $1000 \mathrm{rpm}$ for $8 \mathrm{~min}$. After a twice-wash step with PBS, the cells were re-suspended in $500 \mu \mathrm{L}$ of Binding Buffer. Staining was done by incubating cells with with $5 \mu \mathrm{L}$ Annexin V-FITC and $5 \mu \mathrm{L}$ propidium iodide (PI) $(50 \mu \mathrm{g} / \mathrm{mL})$ (Sangon Biotech, China) for $15 \mathrm{~min}$ at room temperature in the dark. The samples were analyzed by flow cytometry assay. The samples for cell cycle assay were prepared by following subsequent procedures: treatment with $30 \mu \mathrm{g} / \mathrm{mL}$ of TAT-BIR(T34A), TAT-CC(T117A), and TAT-Survivin(T34/117A) for $48 \mathrm{~h}$, fixation with ice-cold 70\% (v/v) ethanol in PBS (pH7.4) at $4^{\circ} \mathrm{C}$ overnight after centrifugation at $300 \mathrm{~g}$ for $5 \mathrm{~min}$, staining with $50 \mu \mathrm{g} / \mathrm{mL}$ PI ( including $50 \mu \mathrm{g} / \mathrm{mL}$ RNase A) for 30 min. The prepared samples were analyzed by flow cytometry (Becton Dickinson, USA).

\section{Autophagy analysis}

Bcap-37 cells $\left(2 \times 10^{4}\right.$ cells/well $)$ were seeded into 6-well plate overnight and then treated with TAT-BIR(T34A), TAT-CC(T117A), and TATSurvivin(T34/117A) for $48 \mathrm{~h}$. The harvested cells were stained for $15 \mathrm{~min}$ with $0.15 \mu \mathrm{mol} / \mathrm{L}$ acridine orange (AO) and washed three times with PBS. The fluorescence was observed with microscopy (OLYPAS, Japan).

\section{Western blot analysis}

Cells were plated onto 6-well plate at a density of $2 \times 10^{4}$ cells/well. The adhered cells were treated by TAT-BIR(T34A), TAT-CC(T117A), or TATSurvivin(T34/117A) at the concentration of $60 \mu \mathrm{g} / \mathrm{mL}$ for $48 \mathrm{~h}$ and washed twice with PBS. The cells were harvested by centrifugation at $1000 \mathrm{rpm}$ for $8 \mathrm{~min}$ and washed once with ice-cold PBS, and then lysed in $200 \mu \mathrm{L}$ RIPA buffer for $30 \mathrm{~min}$ on ice with gentle rocking. The total protein concentration was determined by the BCA protein assay method with BSA as standard. Proteins (50 $\mu \mathrm{g})$ were loaded into each lane and separated by $15 \%$ SDS-PAGE, then were electro-transferred onto pretreated PVDF membranes. The membranes were blocked for $2 \mathrm{~h}$ at room temperature with 5\% non-fat milk in PBS containing $0.05 \%$ Tween-20 (PBST). Then was probed with antibodies against activated caspase-3 (CST, USA), activated caspase-9 (CST, USA), survivin (CST, USA), Cyclin D1 (CST, USA), Beclin-1 (CST, USA), LC3B (CST, USA), and $\beta$-actin (Sangon Biotech, China) for $1 \mathrm{~h}$ at room temperature. After washed with PBST for three times, and the membrane was incubated with the secondary mouse anti-rabbit IgG-HRP for $1 \mathrm{~h}$ at room temperature. Protein bands were visualized on X-ray film with enhanced ECL Western blotting detection reagents (Sangon Biotech, China). The grey values of protein bands have been quantified and statistically analyzed by Image J. 


\section{Statistical analysis}

SPSS software version 22.0 was used for the statistical analysis of the data. Data were expressed as the mean $\pm \mathrm{SD}$ based on the results obtained from at least three independent experiments. A level of $P$ less than 0.05 was considered to be statistically significant.

\section{CONFLICTS OF INTEREST}

The authors declare no potential conflicts of interests.

\section{GRANT SUPPORT}

This work was supported by the National Natural Science Foundation $(31670944,81673345)$, Science and technology innovation action plan of Shanghai (14431904300, 17431904600), Shanghai Pujiang Program (13PJD012), and supported by the National Science Research Project "Significant New Drugs Created" of Eleventh Five-year Plan (2009ZX09103-693).

\section{REFERENCES}

1. Mobahat M, Narendran A, Riabowol K. Survivin as a preferential target for cancer therapy. Int J Mol Sci. 2014; $15: 2494-516$

2. Ju L, Zhang X, Deng Y, Han J, Yang J, Chen S, Fang Q, Yang Y, Jia W. Enhanced expression of Survivin has distinct roles in adipocyte homeostasis. Cell Death Dis. 2017; 8:e2533.

3. Chen X, Duan N, Zhang C, Zhang W. Survivin and Tumorigenesis: Molecular Mechanisms and Therapeutic Strategies. J Cancer. 2016; 7:314-23.

4. Singh N, Krishnakumar S, Kanwar RK, Cheung $\mathrm{CH}$, Kanwar JR. Clinical aspects for survivin: a crucial molecule for targeting drug-resistant cancers. Drug Discov Today. 2015; 20:578-87.

5. $\mathrm{Hu} \mathrm{Y,} \mathrm{Xu} \mathrm{K,} \mathrm{Yagüe} \mathrm{E.} \mathrm{miR-218} \mathrm{targets} \mathrm{survivin} \mathrm{and}$ regulates resistance to chemotherapeutics in breast cancer. Breast Cancer Res Treat. 2015; 151:269-80.

6. Altieri DC. Survivin - The inconvenient IAP. Semin Cell Dev Biol. 2015; 39:91-96.

7. Khan Z, Khan AA, Yadav H, Prasad GB, Bisen PS. Survivin, a molecular target for therapeutic interventions in squamous cell carcinoma. Cell Mol Biol Lett. 2017; 22:8

8. Qi J, Dong Z, Liu J, Peery RC, Zhang S, Liu JY, Zhang JT. Effective Targeting of the Survivin Dimerization Interface with Small-Molecule Inhibitors. Cancer Res. 2016; 76:45362.

9. Verdecia MA, Huang H, Dutil E, Kaiser DA, Hunter T, Noel JP. Structure of the human anti-apoptotic protein survivin reveals a dimeric arrangement. Nat Struct Biol. 2000; 7:602-08.
10. Nogueira-Ferreira R, Vitorino R, Ferreira-Pinto MJ, Ferreira R, Henriques-Coelho T. Exploring the role of posttranslational modifications on protein-protein interactions with survivin. Arch Biochem Biophys. 2013; 538:64-70.

11. De Cesare M, Cominetti D, Doldi V, Lopergolo A, Deraco M, Gandellini P, Friedlander S, Landesman Y, Kauffman MG, Shacham S, Pennati M, Zaffaroni N. Antitumor activity of selective inhibitors of XPO1/CRM1mediated nuclear export in diffuse malignant peritoneal mesothelioma: the role of survivin. Oncotarget. 2015; 6:13119-32. https://doi.org/10.18632/oncotarget.3761.

12. Jeyaprakash AA, Basquin C, Jayachandran U, Conti E. Structural basis for the recognition of phosphorylated histone $\mathrm{h} 3$ by the survivin subunit of the chromosomal passenger complex. Structure. 2011; 19:1625-34.

13. Rosa J, Canovas P, Islam A, Altieri DC, Doxsey SJ. Survivin modulates microtubule dynamics and nucleation throughout the cell cycle. Mol Biol Cell. 2006; 17:1483-93.

14. Mita AC, Mita MM, Nawrocki ST, Giles FJ. Survivin: key regulator of mitosis and apoptosis and novel target for cancer therapeutics. Clin Cancer Res. 2008; 14:5000-05.

15. Li Y, Liu D, Zhou Y, Li Y, Xie J, Lee RJ, Cai Y, Teng L. Silencing of Survivin Expression Leads to Reduced Proliferation and Cell Cycle Arrest in Cancer Cells. J Cancer. 2015; 6:1187-94.

16. Aljaberi AM, Webster JR, Wheatley SP. Mitotic activity of survivin is regulated by acetylation at K129. Cell Cycle. $2015 ; 14: 1738-47$.

17. Wheatley SP, Henzing AJ, Dodson H, Khaled W, Earnshaw WC. Aurora-B phosphorylation in vitro identifies a residue of survivin that is essential for its localization and binding to inner centromere protein (INCENP) in vivo. J Biol Chem. 2004; 279:5655-60.

18. Wheatley SP, Barrett RM, Andrews PD, Medema RH, Morley SJ, Swedlow JR, Lens SM. Phosphorylation by aurora-B negatively regulates survivin function during mitosis. Cell Cycle. 2007; 6:1220-30.

19. Varughese RK, Torp SH. Survivin and gliomas: A literature review. Oncol Lett. 2016; 12:1679-86.

20. Brentnall M, Rodriguez-Menocal L, De Guevara RL, Cepero E, Boise LH. Caspase-9, caspase-3 and caspase-7 have distinct roles during intrinsic apoptosis. BMC Cell Biol. 2013; 14:32.

21. Aspe JR, Wall NR. Survivin-T34A: molecular mechanism and therapeutic potential. Onco Targets Ther. 2010; 3:247-54.

22. Qiang L, Zhao B, Shah P, Sample A, Yang S, He Y. Autophagy regulates DNA repair and controls skin tumorigenesis. J Invest Dermatol. 2016; 136:S20-20.

23. Fu LL, Cheng Y, Liu B. Beclin-1: autophagic regulator and therapeutic target in cancer. Int J Biochem Cell Biol. 2013; 45:921-24.

24. Kang R, Zeh HJ, Lotze MT, Tang D. The Beclin 1 network regulates autophagy and apoptosis. Cell Death Differ. 2011; 18:571-80. 
25. Wang Q, Chen Z, Diao X, Huang S. Induction of autophagydependent apoptosis by the survivin suppressant YM155 in prostate cancer cells. Cancer Lett. 2011; 302:29-36.

26. Chang YJ, Li LT, Chen HA, Hung CS, Wei PL. Silencing survivin activates autophagy as an alternative survival pathway in HCC cells. Tumour Biol. 2014; 35:9957-66.

27. Dai G, Zheng W, Ma X, Wang P. Multisite mutation of monomer survivin with enhanced effect on apoptosis regulation of breast cancer cells. Biomed Pharmacother. 2015; 69:111-18.

28. Zheng WY, Ma XY, Wei DZ, Wang JZ, Liu QH, Ma YS, Yang SL. [Preparation of recombinant HIV-TATm-survivin (T34A) protein and its pro-apoptosis activity to cancer cells in vitro]. [Article in Chinese]. Sheng Wu Gong Cheng Xue Bao. 2006; 22:285-92.

29. Kanter M, Turan G, Usta C, Usta A, Esen HH, Tavlı L, Celik C, Demirkol Y, Kanter B. Survivin and cycline D1 expressions are associated with malignant potential in mucinous ovarian neoplasms. J Mol Histol. 2016; 47:14552.

30. Jane EP, Premkumar DR, Sutera PA, Cavaleri JM, Pollack IF. Survivin inhibitor YM155 induces mitochondrial dysfunction, autophagy, DNA damage and apoptosis in Bcl-xL silenced glioma cell lines. Mol Carcinog. 2017; 56:1251-65.

31. Cho HI, Kim EK, Park SY, Lee SK, Hong YK, Kim TG. Enhanced induction of anti-tumor immunity in human and mouse by dendritic cells pulsed with recombinant TAT fused human survivin protein. Cancer Lett. 2007; 258:18998.

32. Nafisi S, Saboury AA, Keramat N, Neault JF, Tajmir-Riahi HA. Stability and structural features of DNA intercalation with ethidium bromide, acridine orange and methylene blue. J Mol Struct. 2007; 827:35-43.

33. Varghese AC, Fischer-Hammadeh C, Hammadeh ME. Acridine Orange Test for Assessment of Human Sperm DNA Integrity. Sperm Chromatin. 2011:189-199. https:// doi.org/10.1007/978-1-4419-6857-9_13.

34. Salminen A, Kaarniranta K, Kauppinen A. Beclin 1 interactome controls the crosstalk between apoptosis, autophagy and inflammasome activation: impact on the aging process. Ageing Res Rev. 2013; 12:520-34.

35. Ma WH, Liu YC, Xue ML, Zheng Z, Ge YL, and WenHui Ma Y-Cl. Downregulation of survivin expression exerts antitumoral effects on mouse breast cancer cells in vitro and in vivo. Oncol Lett. 2016; 11:159-67.

36. Vachtenheim J, Vlckova K. Insights into the Regulation of Survivin Expression in Tumors. Single Cell Biol. 2016; $5: 139$.

37. Barrett RM, Osborne TP, Wheatley SP. Phosphorylation of survivin at threonine 34 inhibits its mitotic function and enhances its cytoprotective activity. Cell Cycle. 2009; 8:278-83.

38. Ott M, Robertson JD, Gogvadze V, Zhivotovsky B, Orrenius $\mathrm{S}$. Cytochrome c release from mitochondria proceeds by a two-step process. Proc Natl Acad Sci USA. 2002; 99:125963.

39. Bian K, Fan J, Zhang X, Yang XW, Zhu HY, Wang L, Sun JY, Meng YL, Cui PC, Cheng SY, Zhang J, Zhao J, Yang AG, Zhang R. MicroRNA-203 leads to G1 phase cell cycle arrest in laryngeal carcinoma cells by directly targeting survivin. FEBS Lett. 2012; 586:804-09.

40. Suzuki A, Hayashida M, Ito T, Kawano H, Nakano T, Miura M, Akahane K, Shiraki K. Survivin initiates cell cycle entry by the competitive interaction with Cdk4/p16(INK4a) and $\mathrm{Cdk} 2$ /cyclin E complex activation. Oncogene. 2000; 19:3225-34.

41. Ruchaud S, Carmena M, Earnshaw WC. Chromosomal passengers: conducting cell division. Nat Rev Mol Cell Biol. 2007; 8:798-812.

42. Rosenfeldt MT, Ryan KM. The multiple roles of autophagy in cancer. Carcinogenesis. 2011; 32:955-63.

43. Wang YF, Zhang W, He KF, Liu B, Zhang L, Zhang WF, Kulkarni AB, Zhao YF, Sun ZJ. Induction of autophagydependent cell death by the survivin suppressant YM155 in salivary adenoid cystic carcinoma. Apoptosis. 2014; 19:748-58.

44. Roca H, Varsos Z, Pienta KJ. CCL2 protects prostate cancer PC3 cells from autophagic death via phosphatidylinositol 3-kinase/AKT-dependent survivin up-regulation. J Biol Chem. 2008; 283:25057-73.

45. Kimura S, Fujita N, Noda T, Yoshimori T. Monitoring autophagy in mammalian cultured cells through the dynamics of LC3. Methods Enzymol. 2009; 452:1-12.

46. Toton E, Lisiak N, Sawicka P, Rybczynska M. Beclin-1 and its role as a target for anticancer therapy. J Physiol Pharmacol. 2014; 65:459-67. 